Craig S. Moore, $\mathrm{PhD}$

Ariel R. Ase, PhD

Angham Kinsara, MSc

Vijayaraghava T.S. Rao,

$\mathrm{PhD}$

Mackenzie Michell-

Robinson, BSc

Soo Yuen Leong, $\mathrm{PhD}$

Oleg Butovsky, PhD

Samuel K. Ludwin, MD

Philippe Séguéla, $\mathrm{PhD}$

Amit Bar-Or, MD

Jack P. Antel, MD

Correspondence to

Dr. Moore:

craig.moore@mun.ca
Supplemental data at Neurology.org/nn

\title{
P2Y12 expression and function in alternatively activated human microglia
}

OPEN

ABSTRACT

Objective: To investigate and measure the functional significance of altered P2Y12 expression in the context of human microglia activation.

Methods: We performed in vitro and in situ experiments to measure how P2Y12 expression can influence disease-relevant functional properties of classically activated (M1) and alternatively activated (M2) human microglia in the inflamed brain.

Results: We demonstrated that compared to resting and classically activated (M1) human microglia, P2Y12 expression is increased under alternatively activated (M2) conditions. In response to ADP, the endogenous ligand of P2Y12, M2 microglia have increased ligand-mediated calcium responses, which are blocked by selective P2Y12 antagonism. P2Y12 antagonism was also shown to decrease migratory and inflammatory responses in human microglia upon exposure to nucleotides that are released during CNS injury; no effects were observed in human monocytes or macrophages. In situ experiments confirm that P2Y12 is selectively expressed on human microglia and elevated under neuropathologic conditions that promote $T_{h} 2$ responses, such as parasitic CNS infection.

Conclusion: These findings provide insight into the roles of M2 microglia in the context of neuroinflammation and suggest a mechanism to selectively target a functionally unique population of myeloid cells in the CNS. Neurol Neuroimmunol Neuroinflamm 2015;2:e80; doi: 10.1212/ NXI.0000000000000080

\section{GLOSSARY}

BSA $=$ bovine serum albumin; $\left[\mathrm{Ca}^{2+}\right]_{\mathbf{L}}=$ intracellular calcium; $\mathbf{C S F}=$ colony-stimulating factor; $\mathbf{F B S}=$ fetal bovine serum; IFN = interferon; IL = interleukin; LPS = lipopolysaccharide; $\mathbf{M D M}=$ monocyte-derived macrophage; $\mathbf{m R N A}=$ messenger RNA; MS = multiple sclerosis; TNF = tumor necrosis factor .

In vitro studies have previously demonstrated several phenotypic and functional differences between human monocyte-derived macrophages (MDMs) and microglia in the context of cell migration, phagocytosis, and immunoregulatory and effector functions. ${ }^{1-6}$ The distinct properties of myeloid cell subtypes suggest that they may differentially contribute to mechanisms related to both CNS injury and repair. While several technologies enable us to distinguish between different myeloid cell subpopulations in mice $^{7-9}$ and have contributed to our understanding of myeloid cell origin and function, they have yet to provide direct translation and relevance in humans.

P2Y12 has been identified as a receptor that robustly distinguishes microglia from other myeloid lineage cells. ${ }^{10}$ The P2Y12 receptor is an ADP-responsive G protein-coupled receptor expressed on the surface of platelets and is the pharmacologic target of several antithrombotic agents. ${ }^{11}$ In the CNS, P2Y12 expression is limited to the ramified processes of microglia, which

\footnotetext{
From the Division of BioMedical Sciences (C.S.M.), Neuroscience, Memorial University of Newfoundland and Labrador, St. John's, Newfoundland, Canada; Neuroimmunology Unit (C.S.M., A.A., A.K., V.T.S.R., M.M.-R., S.Y.L., P.S., A.B.-O., J.P.A.), Department of Neurology and Neurosurgery, Montreal Neurological Institute and Hospital, McGill University, Montreal, Quebec, Canada; Center for Neurologic Diseases (O.B.), Department of Neurology, Brigham and Women's Hospital, Harvard Medical School, Boston, MA; and Department of Pathology and Molecular Medicine (S.K.L.), Queens University, Kingston, Ontario, Canada.

Funding information and disclosures are provided at the end of the article. Go to Neurology.org/nn for full disclosure forms. The Article Processing Charge was paid by the authors.

This is an open access article distributed under the terms of the Creative Commons Attribution-Noncommercial No Derivative 3.0 License, which permits downloading and sharing the work provided it is properly cited. The work cannot be changed in any way or used commercially.
} 
likely facilitates the detection of nucleotides upon injury. ${ }^{12}$ It is interesting that loss of P2Y12 expression in microglia results in decreased process extension and migration following focal injury. ${ }^{12,13}$ In humans, the role of P2Y12 expression in microglia is unknown. Herein, we investigated the significance of P2Y12 expression in the context of human brain injury and repair. Our results confirm that P2Y12 is a unique marker of human microglia, increases following interleukin (IL) -4 and IL-13 activation, and mediates cell migration and inflammatory responses. Identifying P2Y12 as a molecule associated with the M2 tissue regenerative phenotype ${ }^{14-16}$ may help to discover novel therapeutic targets and mechanisms that promote $\mathrm{CNS}$ repair.

METHODS Standard protocol approvals, registrations, and patient consents. All institutional ethics approval was obtained according to Canadian Institutes of Health Research guidelines.

Human fetal and adult microglia isolation, culture, and polarization. Human fetal brain tissue was obtained from the Fetal Tissue Repository (Albert Einstein College of Medicine, Bronx, NY). Human adult microglia were isolated from healthy brain tissue of patients undergoing brain surgery for intractable epilepsy. Human fetal and adult microglia were cultured in 5\% DMEM and 5\% MEM, respectively, with 5\% fetal bovine serum (FBS), penicillin/ streptomycin, and glutamine. Cell polarization was performed over 48 hours, according to previously published methods. ${ }^{1,17}$ Briefly, microglia were polarized to the M1 phenotype using granulocyte macrophage colony-stimulating factor (GM-CSF) $(5 \mathrm{ng} / \mathrm{mL})$, interferon (IFN)- $\gamma(20 \mathrm{ng} / \mathrm{mL})$, and lipopolysaccharide (LPS) (serotype 0127:B8, $100 \mathrm{ng} / \mathrm{mL}$ ). M2 cells were polarized using macrophage colony-stimulating factor (M-CSF) $(25 \mathrm{ng} / \mathrm{mL})$, IL-4 $(20 \mathrm{ng} / \mathrm{mL})$, and IL-13 $(20 \mathrm{ng} / \mathrm{mL})$.

Human MDM culture and polarization. Human peripheral blood mononuclear cells were isolated by Ficoll separation from the blood of healthy volunteers. CD14 ${ }^{+}$cells were positively selected using immunomagnetic bead selection (Miltenyi Biotec, Auburn, CA). Macrophage differentiation was performed over 5 days by culturing monocytes $\left(5 \times 10^{5}\right.$ cells $\left./ \mathrm{mL}\right)$ in RPMI supplemented with $10 \%$ FBS, M-CSF $(25 \mathrm{ng} / \mathrm{mL})$, penicillin/ streptomycin, and glutamine. MDMs were polarized using the protocol described above.

Immunocytochemistry/immunohistochemistry. Immunocytochemistry was performed using a rabbit polyclonal antiP2Y12 antibody ${ }^{10}$ (generated by Dr. H. Weiner, Harvard University, Cambridge, MA), a monoclonal anti-CD68 antibody (Dako, Burlington, Ontario, Canada; 1:100), and appropriate secondary antibodies. For human brain sections, slides were deparaffinized and antigen retrieval was performed using a $0.01 \mathrm{M}$ sodium citrate buffer solution ( $\mathrm{pH}$ 6.0) for 15 minutes in the microwave on high setting.

RNA isolation and reverse transcription quantitative realtime PCR. Total RNA was isolated using standard Trizol protocols and DNase-treated (Qiagen, Germantown, MD). TaqMan quantitative real-time PCR was used to measure messenger RNA (mRNA) expression levels for all mRNAs. Relative gene expression data were calculated according to the $\Delta \Delta \mathrm{Ct}$ method. ${ }^{18}$

Flow cytometry. Human microglia were collected by gently scraping and blocked in FACS buffer supplemented with 10\% normal human serum and normal mouse IgG $(3 \mu \mathrm{g} / \mathrm{mL})$. Cells were then incubated at $4^{\circ} \mathrm{C}$ for 30 minutes with either a control isotype antibody directly conjugated with Alexa647 (BD Biosciences, Mississauga, Ontario, Canada) or a polyclonal rabbit anti-P2Y12 antibody (1:100) followed by an anti-IgG1Alexa647 (1:100). After washing, cells were fixed in $1 \%$ formaldehyde and flow cytometry was performed using a FACSCalibur (BD Biosciences)

Ratiometric measurement of intracellular calcium. Microglia were loaded with fura-2 AM $(5 \mu \mathrm{M}$, Molecular Probes, Life Technologies, Grand Island, NY) in Ringer solution containing $\mathrm{NaCl}(130 \mathrm{mM}), \mathrm{KCl}(5 \mathrm{mM}), \mathrm{CaCl}_{2}$ (2 $\mathrm{mM}), \mathrm{MgCl}_{2}(1 \mathrm{mM})$, HEPES $(10 \mathrm{mM})$, glucose $(8 \mathrm{mM})$ ( $\mathrm{pH} 7.4$ ), and $1 \%$ bovine serum albumin (BSA) for 30 minutes at $37^{\circ} \mathrm{C}$. Prior to imaging, microglia were washed and incubated for an additional 30 minutes. Fluorescence was measured at 510 $\mathrm{nm}$ and recorded with a high-resolution camera (CoolSNAP HQ2, Roper Scientific/Photometrics, Tucson, AZ). Pairs of 340 $\mathrm{nm}$ and $380 \mathrm{~nm}$ images were acquired and calculated using Metafluor 7.0 software (Molecular Devices, Sunnyvale, CA). The $340 / 380 \mathrm{~nm}$ emission ratios were proportional to intracellular calcium levels.

Cell migration assays. Migration assays were performed using Boyden-type 96-well plates according to manufacturer's instructions (Neuro Probe, Gaithersburg, MD). Cells were suspended in media containing $0.5 \%$ BSA for 1 hour and pretreated with PSB0739 $(10 \mu \mathrm{M})$ or vehicle (DMSO). ATP or $\operatorname{ADP}(1-300 \mu \mathrm{g} / \mathrm{mL})$ was added to induce chemotaxis. Polycarbonate filters $(10 \mu \mathrm{m}$ [microglia] or $5 \mu \mathrm{m}$ [monocytes] pore size) were placed in contact with media and cells were added $\left(10^{6}\right.$ cells $\left./ \mathrm{mL}\right)$ atop the filter. Following incubation (4 hours at $37^{\circ} \mathrm{C}$ ), the filter surface was washed, fixed with $2 \%$ PFA, and stained using a $0.04 \%$ crystal violet.

Migration studies were also performed using microfluidic chambers with $10-\mu \mathrm{m}$ diameter channels (1 $\mathrm{mm}$ in length) (ANANDA, McGill University, Montreal, Quebec, Canada). Microglia were pretreated with either PSB0739 $(10 \mu \mathrm{M}$; R\&D Systems, Minneapolis, MN) or vehicle for 1 hour and then plated $\left(10^{6}\right.$ cells $\left./ \mathrm{mL}\right)$ in the upper chamber. Media alone or media containing ADP $(300 \mu \mathrm{M})$ was added to the lower chamber as a chemotactic agent. Following 3 days and supplementing ADP each day, cells were fixed, washed, and stained with DAPI and a FITC-conjugated CD68 antibody (1:40, BD Biosciences). Images were visualized using fluorescence microscopy (Leica, Wetzlar, Germany) and OpenLab software (PerkinElmer, Waltham, MA). The distance within the migration chamber for each nucleated cell was measured.

ELISAs. Human tumor necrosis factor (TNF) and IL-6 ELISAs were performed according to the manufacturer's instructions (BD Biosciences). LPS activation (100 ng/mL) was used in all experiments as a positive control. All results are presented as percent of maximal response relative to ADP treatment $(200 \mu \mathrm{M})$.

Statistics. All statistical analyses were performed using Prism 5.0 (GraphPad Software, La Jolla, CA). Data are presented as mean \pm SEM. A one-way analysis of variance with Tukey post hoc 
tests or unpaired Student $t$ test was used to determine differences between the experimental conditions; $p<0.05$ was considered statistically significant.

RESULTS P2Y12 expression is significantly elevated in human microglia compared to MDMs. Compared to MDMs, P2Y12 expression was highly elevated in both fetal and adult microglia. Delta cycle threshold values were significantly lower in both human fetal and adult microglia compared with MDMs, indicative of greater expression (figure 1A). To confirm protein expression, co-immunocytochemistry was performed using anti-CD68 and anti-P2Y12 antibodies. Human microglia positively stained for P2Y12, while no staining was observed for MDMs (figure 1B). As a positive control, rat microglia positively stained for P2Y12, as previously described $^{10}$ (figure e-1A at Neurology.org/nn).

Alternatively polarized "M2" human microglia significantly upregulate P2Y12 expression. To determine whether activation of human microglia influenced

\section{Figure 1 P2Y12 expression is significantly elevated in human microglia compared to monocyte-derived macrophages}

A

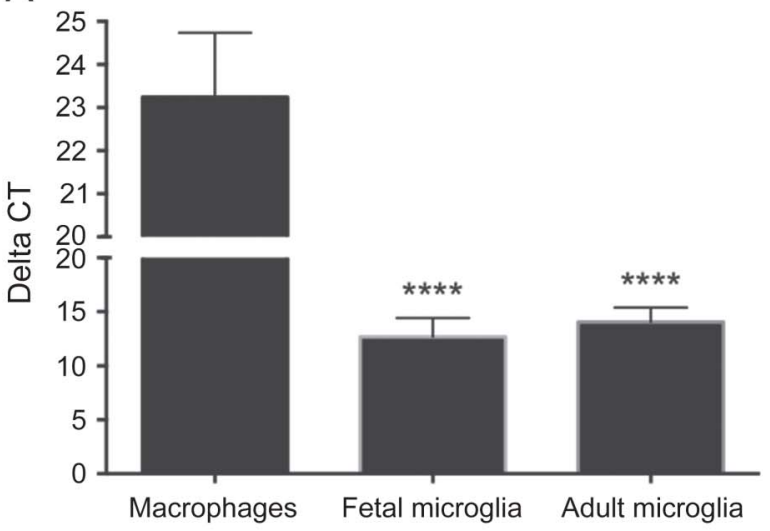

B
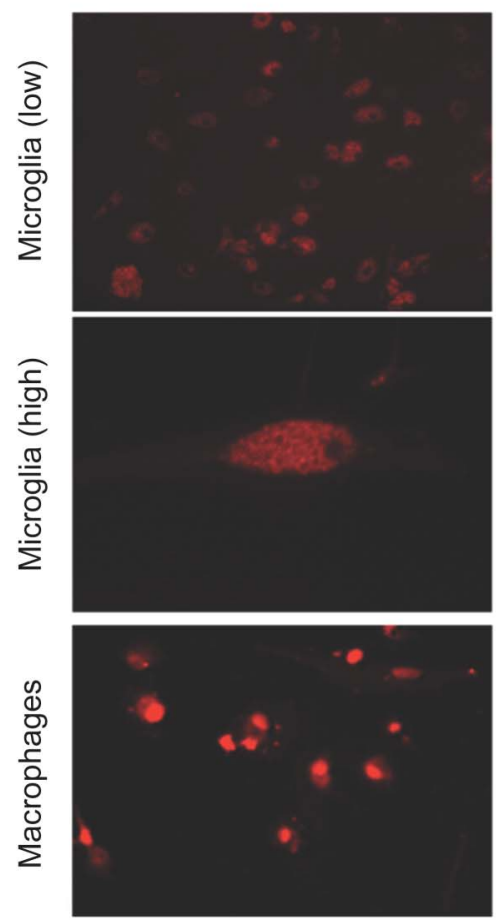

$\mathrm{P} 2 \mathrm{Y} 12$
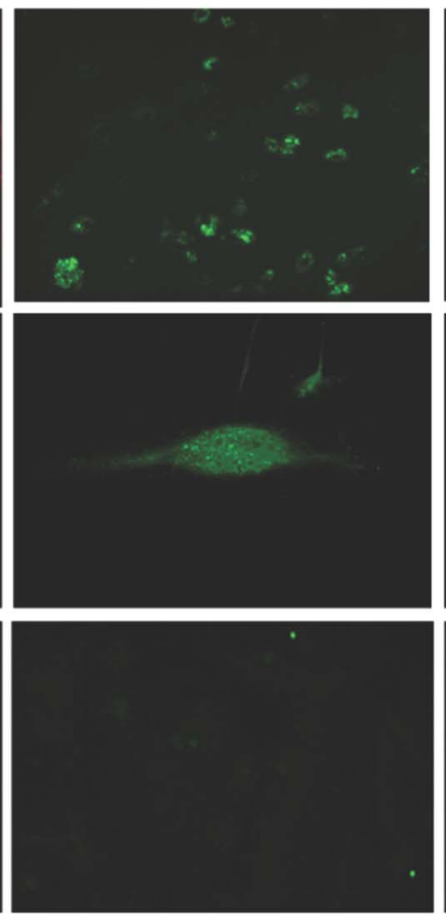

Merge
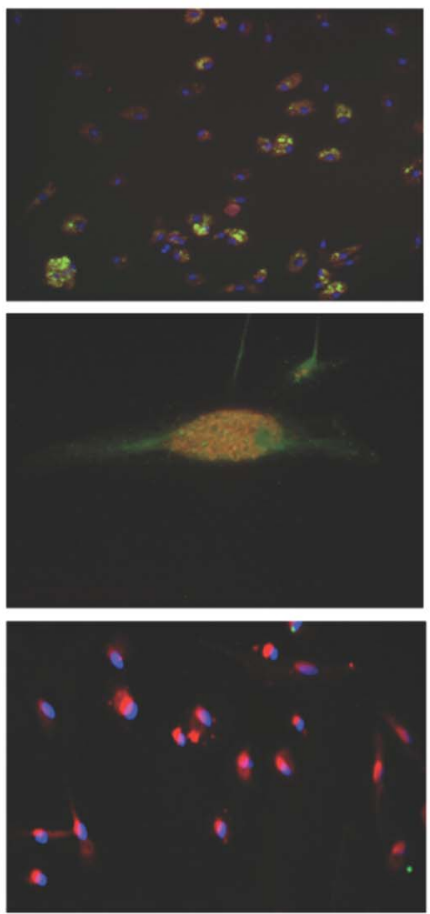

(A) Using TaqMan quantitative real-time PCR, P2Y12 expression was measured in RNA isolated from resting human monocyte-derived macrophages and microglia (both fetal and adult). Compared to monocyte-derived macrophages, delta cycle threshold $\left(\mathrm{C}_{\mathrm{T}}\right)$ values were much lower in both human fetal and adult microglia populations, which is indicative of higher $\mathrm{P} 2 Y 12$ expression. Error bars represent mean $\pm \mathrm{SEM} ; \mathrm{n}=4$ samples/condition; $* * * * p<0.0001$. (B) Using immunocytochemistry, resting $\mathrm{CD} 8^{+}$human microglia expressed P2Y12; no immunoreactivity was observed in resting macrophages. 


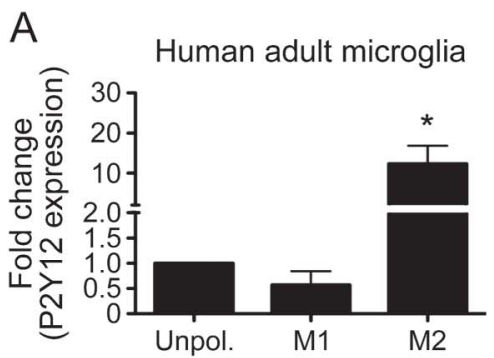

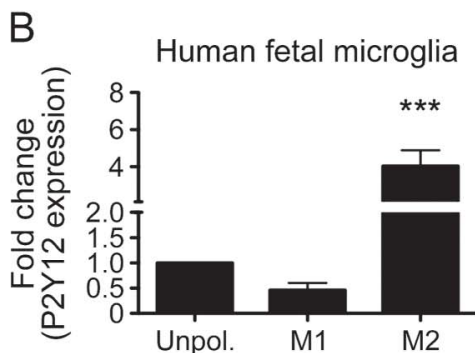

$\mathrm{E}$
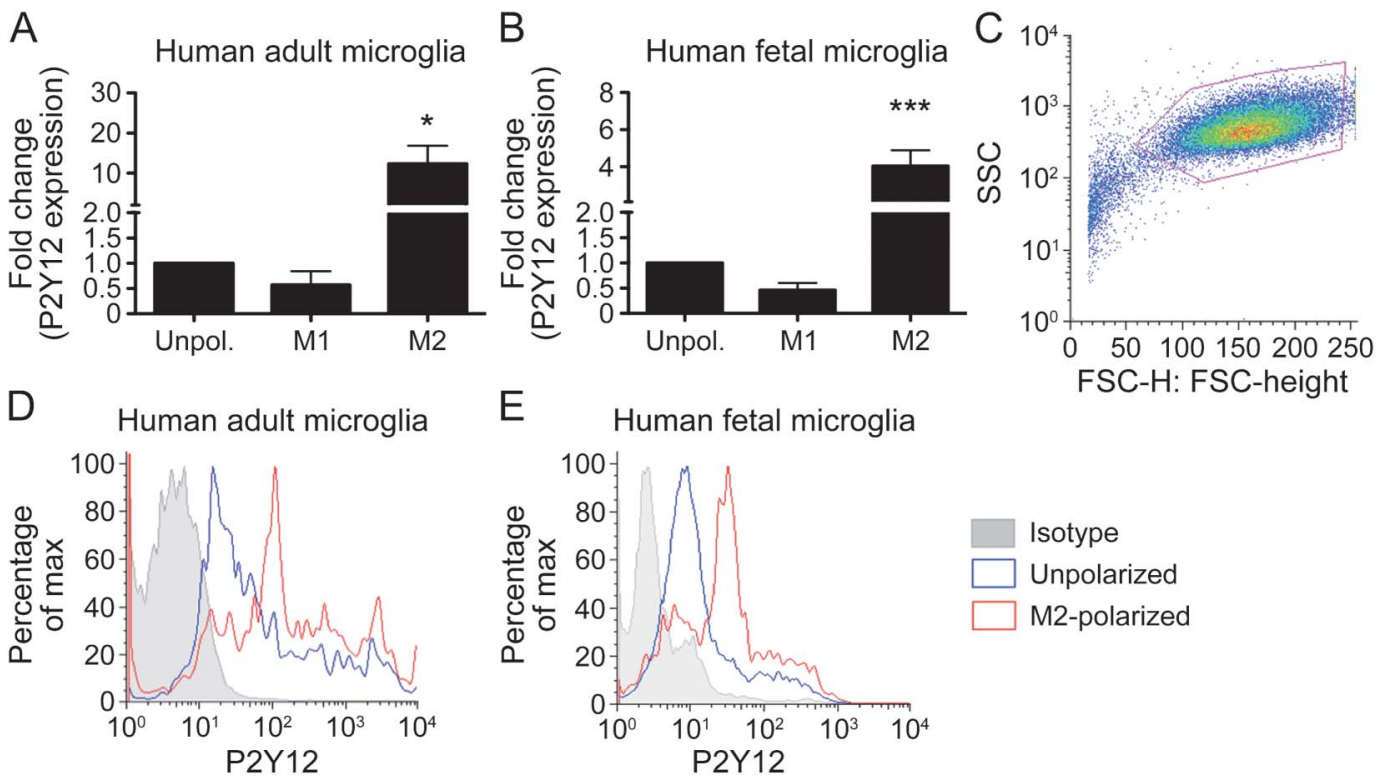

(A, B) Using TaqMan quantitative real-time PCR, P2Y12 expression was measured in M1- and M2-polarized human microglia (both adult and fetal). Compared to unpolarized (Unpol.) and M1-polarized cells, M2 microglia had significantly elevated P2Y12 expression. Error bars represent mean $\pm S E M ; n=5 /$ condition for microglia, $n=3 /$ condition for macrophages; $* p<0.05, * * * p<0.001$ compared to unpolarized. (C) Using flow cytometry, gating on the live human microglia population, mean fluorescence intensity of P2Y12 was increased in M2-polarized (red line) adult microglia (D) and fetal microglia (E) compared to resting conditions (blue line). Shaded histogram represents isotype control.

expression of P2Y12, cells were polarized to either M1 (classical activation) or M2 (alternative activation). Compared to unpolarized microglia, P2Y12 mRNA expression was significantly increased in M2-polarized cells (10-fold change in adult microglia [figure 2A] and 4-fold change in fetal microglia [figure 2B]). Decreased expression was observed in M1-polarized cells, although results were not statistically significant. Flow cytometry experiments confirmed the increase in surface protein expression of $\mathrm{P} 2 \mathrm{Y} 12$ whereby the mean fluorescence intensity was increased in M2-polarized adult microglia (figure 2D) and M2-polarized fetal microglia (figure 2E) compared to resting state.

ADP-induced intracellular calcium responses clearly distinguish human microglia from macrophages and are enhanced under alternatively polarizing M2 conditions. To further validate the presence of functional P2Y12 receptors at the surface of human microglia, prominent intracellular calcium $\left(\left[\mathrm{Ca}^{2+}\right]_{\mathrm{i}}\right)$ transients were observed in human fetal microglia following a short application of ADP (figure 3, A and B). Since ADP is also an agonist of $\mathrm{P} 2 \mathrm{Y} 1$ and $\mathrm{P} 2 \mathrm{Y} 13$, the $\mathrm{P} 2 \mathrm{Y} 12$-selective antagonist PSB0739 was used to assess the selective contribution of P2Y12 to ADP-evoked $\left[\mathrm{Ca}^{2+}\right]_{\mathrm{i}}$ responses. Treatment with PSB0739 $(10 \mu \mathrm{M})$ suppressed ADP-induced $\left[\mathrm{Ca}^{2+}\right]_{\mathrm{i}}$ transients (figure 3, A and $\mathrm{B}$ ), confirming $\mathrm{P} 2 \mathrm{Y} 12$ as the primary ADP receptor on human microglia. In contrast, ADP-induced $\left[\mathrm{Ca}^{2+}\right]_{\mathrm{i}}$ responses were small or absent in human MDMs, yet they responded to ATP, likely through Gq-coupled P2Y2 receptors (figure 3, C and D). To measure across species, similar experiments were performed using rat microglia and produced similar transients (figure $\mathrm{e}-1, \mathrm{~B}$ and C). Differential ADP-evoked $\left[\mathrm{Ca}^{2+}\right]_{\mathrm{i}}$ responses were also observed between unpolarized, M1-polarized, and M2-polarized human microglia. Compared to unpolarized microglia, transients were significantly larger in the M2-polarized cells (figure 3, E-G). No differences between unpolarized and M1-polarized microglia were observed (figure e-2). In both unpolarized and M2-polarized cells, ADP-induced $\left[\mathrm{Ca}^{2+}\right]_{\mathrm{i}}$ responses were blocked by a selective P2Y12 antagonist.

ADP-induced migration of human microglia is attenuated by a P2Y12 antagonist. To compare and measure how migration of human myeloid cells may be influenced by targeting P2Y12, microfluidic chambers and Boyden-type assays were used. In both assays, ADP induced a dose-dependent increase in migration. Microglia pretreated with PSB0739, a selective P2Y12 antagonist, significantly decreased migration (figure 4, A-C); this was further quantified using microfluidic chambers (mean distance of $317 \mu \mathrm{m}$ compared to $532 \mu \mathrm{m}$ in control; figure 4, D-F; figure e-3). No migratory 
Figure 3 ADP-evoked intracellular calcium responses discriminate between human microglia and macrophages while increased ADP-evoked intracellular calcium responses are observed in M2-polarized human microglia

A

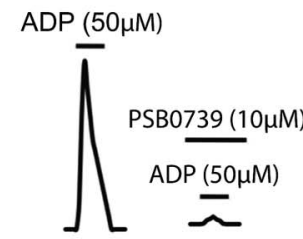

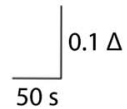

C

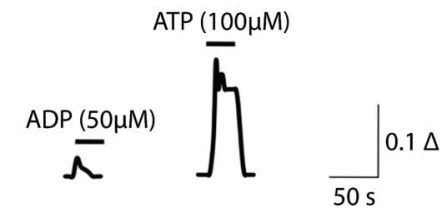

E

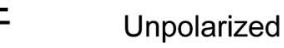

$\operatorname{ADP}(50 \mu \mathrm{M})$
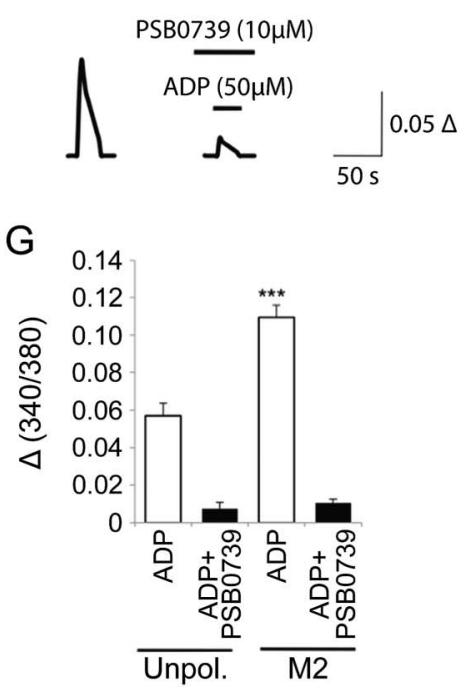

(A) Averaged traces of intracellular calcium $\left(\left[\mathrm{Ca}^{2+}\right]_{i}\right)$ levels following a short application of ADP in fetal human microglia. The P2Y12 selective antagonist PSB0739 strongly blocks ADP-induced $\left[\mathrm{Ca}^{2+}\right]_{i}$. (B) Quantification of ADP-evoked $\left[\mathrm{Ca}^{2+}\right]_{i}$ responses in the absence or presence of PSB0739. (C) ADP-evoked $\left[\mathrm{Ca}^{2+}\right]_{i}$ is minimal in human macrophages; however the cells respond strongly to ATP. (D) Quantification of ADP- and ATP-induced $\left[\mathrm{Ca}^{2+}\right]_{i}$ transients. (E) Averaged traces of $\left[\mathrm{Ca}^{2+}\right]_{i}$ levels following application of ADP in unpolarized human fetal microglia and (F) comparison with responses to ADP in M2-polarized cells. (G) ADP-evoked $\left[\mathrm{Ca}^{2+}\right]_{i}$ responses in both unpolarized (Unpol.) and M2-polarized cells are blocked by the P2Y12 antagonist PSB0739, summary quantification. Error bars represent mean $\pm \mathrm{SEM} ; \mathrm{n}=14-35$ cells/condition; $* * * p<0.001$.

responses were observed in peripheral-derived human monocytes (figure e-4).

ADP-induced inflammatory responses in human microglia are attenuated by a P2Y12 antagonist. To determine whether pharmacologic inhibition of the
P2Y12 receptor could also influence inflammatory responses, human microglia were exposed to ADP in the presence or absence of PSB0739. In adult and fetal microglia, ADP induced a dose-dependent increase in TNF- $\alpha$, with peak responses at 200 $\mu \mathrm{M}$; no effect was observed with ATP (data not shown). Preexposure of PSB0739 for 1 hour resulted in a dose-dependent decrease in TNF- $\alpha$ following stimulation with ADP (figure 5, A and B). No effect was observed in MDMs (figure e-5). A $75 \%$ decrease in TNF- $\alpha$ levels was measured in adult and fetal microglia treated with $10 \mu \mathrm{M}$ and $50 \mu \mathrm{M}$ PSB0739, respectively. Decreased IL-6 expression was also measured; however, results were not statistically significant (figure 5, C and D).

P2Y12 is highly expressed in $\mathrm{CD}^{+}{ }^{+}$cells during parasitic brain infection. Previous reports have demonstrated that parasitic helminth infections induce a robust $\mathrm{T}_{\mathrm{h}} 2$ response. ${ }^{19-21}$ Considering $\mathrm{T}_{\mathrm{h}} 2$ cytokines are known to promote an M2-like cell phenotype, we hypothesized that increased P2Y12 expression could be observed in a $\mathrm{T}_{\mathrm{h}} 2$-driven CNS inflammatory condition such as Schistosoma mekongi.22 Neuropathologic assessment demonstrated the presence of chronic granulomata within the brain parenchyma consisting of multinucleated giant cells surrounding spaces containing chitinous helminthic tissue and ova. Surrounding infiltrates consisted of macrophages, lymphocytes, and plasma cells (figure 6A). A marked reactive astrocytic response was seen in the adjacent parenchyma. Within the granulomas, immunohistochemistry experiments showed the presence of several $\mathrm{CD} 68^{+} / \mathrm{CD} 163^{+}$(M2 marker) cells staining positive for P2Y12 (figure $6, \mathrm{~B}$ and $\mathrm{C})$.

DISCUSSION In the inflamed CNS, activated resident microglia and blood-derived macrophages are a heterogeneous population of cells that can differentially contribute to pathophysiologic mechanisms related to injury and repair. Despite direct in vitro evidence supporting these observations, the ability to reliably distinguish these cell types in situ remains challenging. Several recent publications have used novel genomic and proteomic technologies to assign unique molecular signatures to different myeloid cell populations. ${ }^{10,23}$ In a recent study, detailed flow cytometry and immunohistochemical analyses were performed using both naïve and experimental autoimmune encephalomyelitis mice chimeras (CX3CR1-GFP ${ }^{+/-}$-wildtype), whereby peripheral monocytes were distinguishable from microglia. ${ }^{24}$ In vivo, these experiments demonstrated that resident GFP-microglia expressed P2Y12, whereas recruited GFP+ monocytes did not. ${ }^{10}$ In the 
A
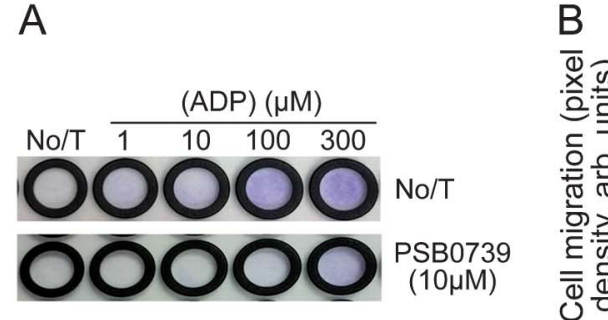
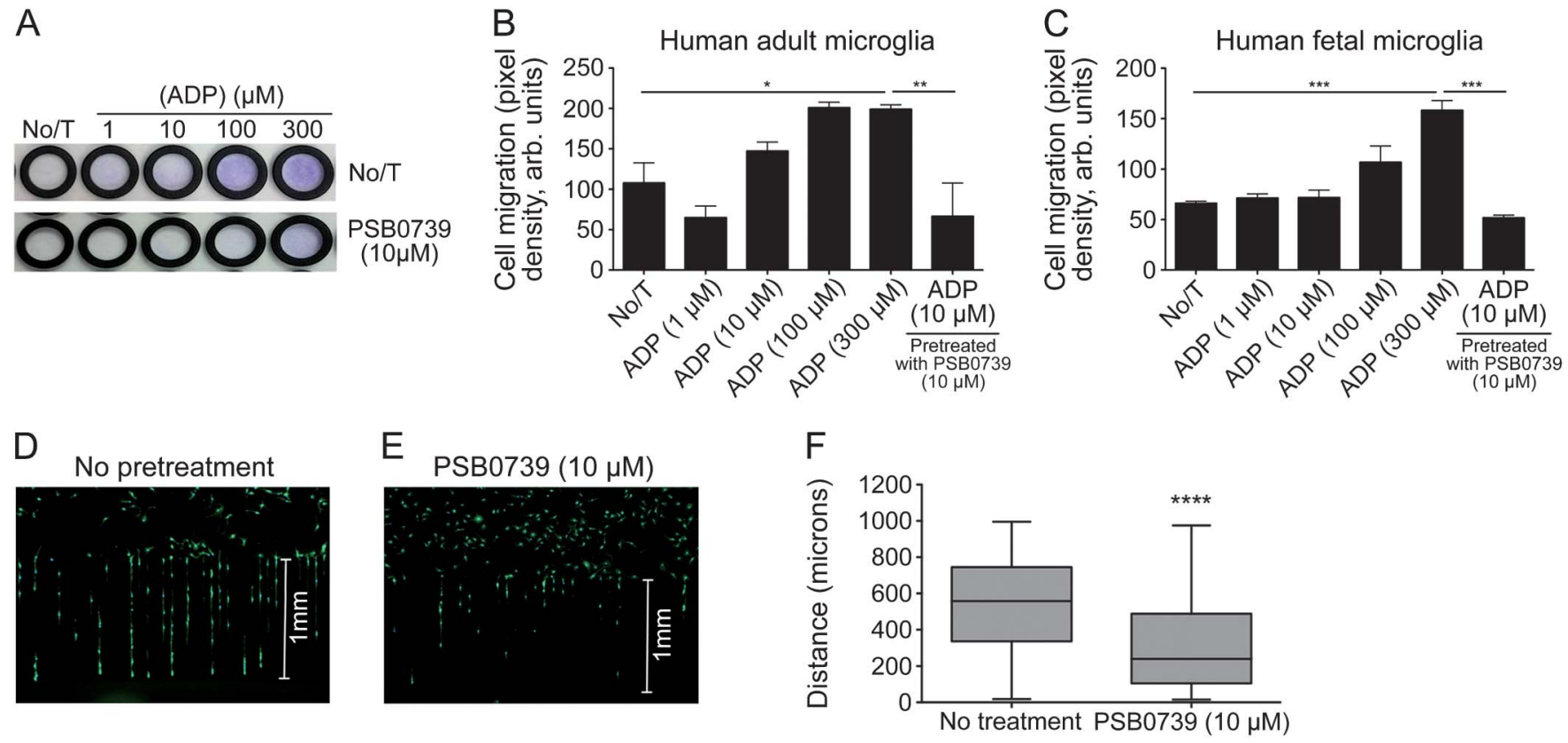

(A) Using $10 \mu \mathrm{m}$ cell migration chambers followed by crystal violet staining, ADP induced a significant migration of human microglia, whereas a 30 -minute preexposure of a P2Y12 antagonist (PSB0739; $10 \mu \mathrm{M}$ ) significantly decreased ADP-induced migration after 6 hours. Results were quantified in both adult (B) and fetal (C) microglia. (D-F) Using silicon migration chambers, preexposure of a P2Y12 antagonist also significantly reduced migratory distance of human microglia. For panels $B$ and $C$, error bars represent mean $\pm S E M ; n=4 /$ condition for microglia. For panel $F$, shaded box represents $95 \%$ confidence interval; error bars represent minimum and maximum values. ${ }^{*} p<0.05, * * p<0.01,{ }^{* * *} p<0.001, * * * * p<0.0001$

present study, we have validated P2Y12 as a receptor that is exclusively expressed on human microglia. Using human fetal and adult microglia, we report that P2Y12 expression is enhanced under alternatively activated (M2; IL-4 \& IL-13) conditions, mediates cell migration, and participates in eliciting acute proinflammatory response toward danger-associated molecules that are released during CNS injury.

$\mathrm{P} 2 \mathrm{Y} 12$ is a $\mathrm{G}_{\mathrm{i} / 0^{-}}$-coupled purinergic receptor that was initially identified on platelets and is responsible for platelet activation during the blood clotting process. ${ }^{25} \mathrm{P} 2 \mathrm{Y} 12$ antagonists have therefore been developed as antithrombotic agents to reduce the risk of heart attack and stroke in high-risk patients. Beyond platelets, P2Y12 expression was first described in rodent microglia ${ }^{26}$ and has been implicated in cell activation and migration. ${ }^{12,27,28}$ In normal rodent microglia, LPS rapidly decreases P2Y12 expression, suggesting that this receptor is a primary site by which nucleotides induce very early migration in response to pathogens and/or local injury. ${ }^{12}$ In $\mathrm{P} 2 \mathrm{Y}_{12}{ }^{-/-}$mice, microglia fail to migrate or extend processes toward nucleotides in vitro and in vivo. ${ }^{12} \mathrm{P} 2 \mathrm{Y} 12$ knockdown using morpholinos in zebrafish also resulted in a complete block of microglial responses to injury. ${ }^{13}$

In our experiments, we confirmed that P2Y12 is highly expressed on human microglia compared to MDMs (figure 1). A direct comparison of P2Y12 expression between fetal and adult microglia revealed that expression was greater in fetal cells than adult microglia, which is consistent with results demonstrating that P2Y12 expression declines with age. ${ }^{29}$ In response to ADP, P2Y12 receptor signaling induces a rapid release of $\left[\mathrm{Ca}^{+}\right]_{\mathrm{i}}$, which activates several downstream signaling pathways. ${ }^{30}$ Using a selective P2Y12 antagonist, PSB0739, we demonstrated that ADP-induced $\left[\mathrm{Ca}^{+}\right]_{\mathrm{i}}$ is dramatically abrogated in human microglia. In MDMs, ADP did not induce an increase in $\left[\mathrm{Ca}^{+}\right]_{\mathrm{i}}$, thus validating our initial observations that P2Y12 expression was minimal to negligible in blood-derived myeloid cells (figure 3). In assays designed to measure P2Y12-dependent migration of human myeloid cells to ADP, an important signal that promotes microglial migration and recruitment, we observed that human microglia dosedependently migrate toward ADP. This response was blocked with preexposure to the P2Y12 antagonist (figure 5).

Both microglia and macrophages are dependent on distinct activation signals that are required to induce different functional properties, often referred to as M1 and M2 polarization. While rodent and human macrophages can exhibit a spectrum of activation phenotypes both in vivo and in vitro, ${ }^{31}$ it should be noted that tissue-resident myeloid cells (e.g., microglia) are a distinct myeloid cell subset that 
A

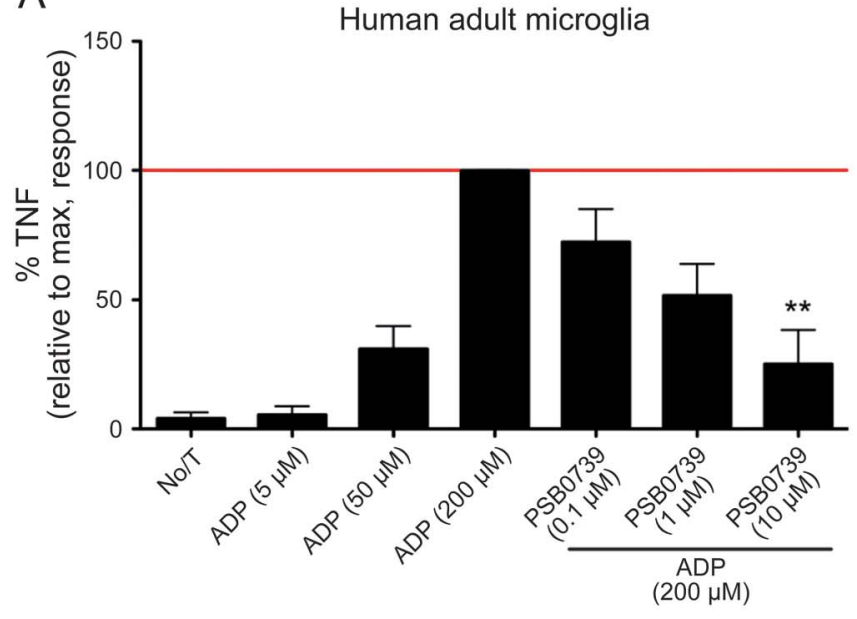

C

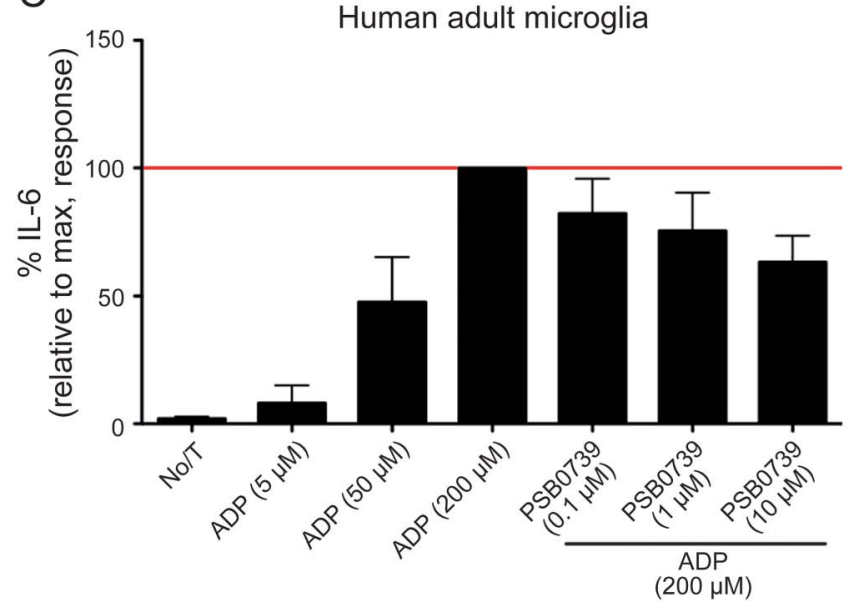

B

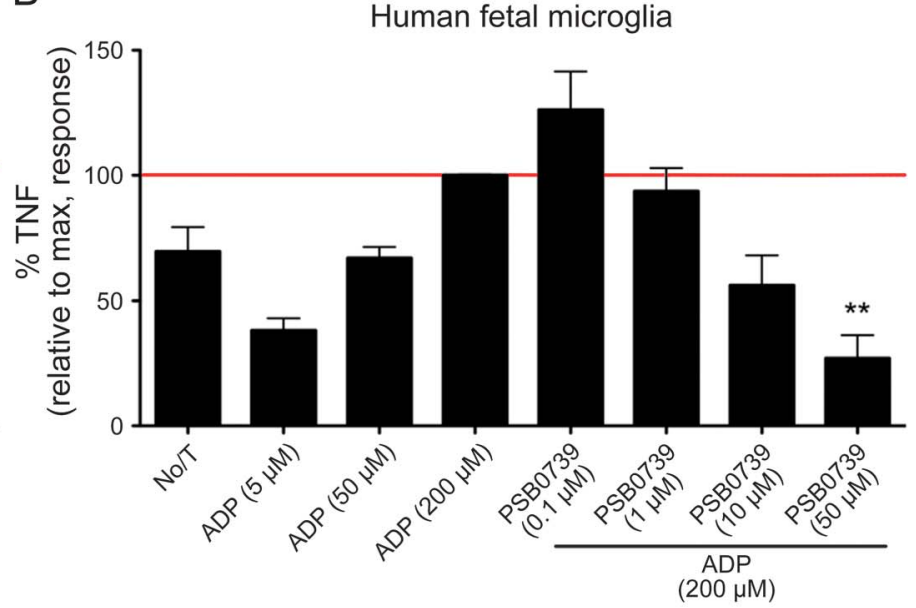

D

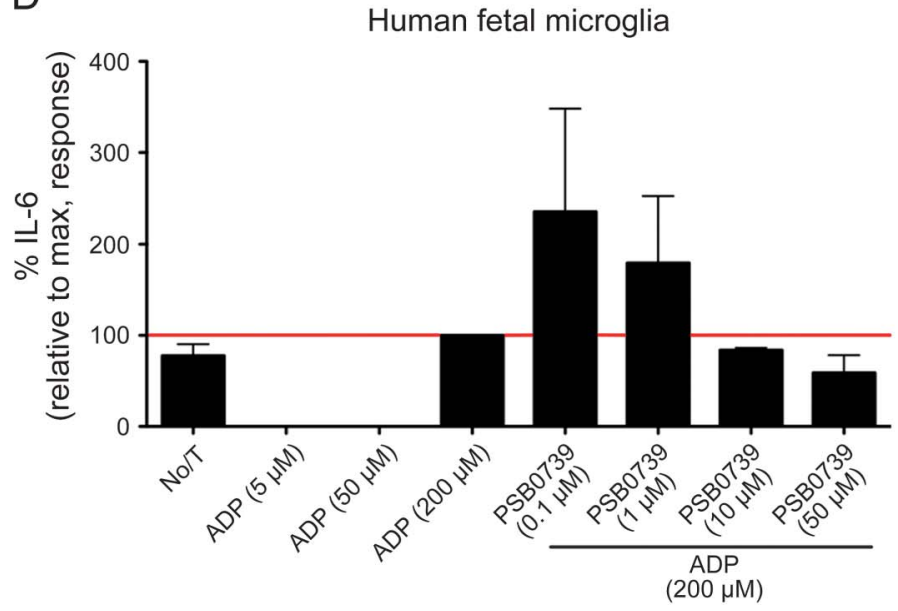

Increasing concentrations of ADP (5, 50, and $200 \mu \mathrm{M})$ increased tumor necrosis factor (TNF) and interleukin (IL)-6 release in human adult microglia (A, C) and fetal microglia (B, D), with maximal response reached at $200 \mu \mathrm{M}$ after 6 hours. A 1-hour pretreatment with a P2Y12 receptor antagonist (PSB0739) dosedependently decreased TNF and IL- 6 cytokine expression induced by ADP $(200 \mu \mathrm{M})$ as measured by ELISAs. Error bars represent mean \pm SEM; $\mathrm{n}=$ $4 /$ condition; **p $<0.01$ compared to ADP $(200 \mu \mathrm{M})$ treatment alone.

requires further investigation with respect to how different modes of activation can influence their cellular properties. For this reason, we have investigated how IL-4 and IL-13 can lead to a microglia phenotype, which is similar in an in situ microenvironment known to express high levels of these cytokines. Previously, we have extensively profiled different activation states of human microglia and characterized several different phenotypic markers (e.g., gene, microRNA, and protein) and functional properties. ${ }^{1,5}$ In vitro, M1 microglia (IFN- $\gamma$ \& LPS stimulated) are implicated as potential mediators of tissue injury, whereas M2 (IL-4/13) cells can produce antiinflammatory molecules and have been reported to significantly mediate repair mechanisms in animal models of stroke, ${ }^{32}$ spinal cord injury, ${ }^{18}$ and demyelination. ${ }^{17}$ Under proinflammatory conditions, in vitro and in situ studies have demonstrated that
P2Y12 expression is decreased in rodent microglia and results in the inability to migrate toward an ADP gradient. ${ }^{28}$ In postmortem samples from the cerebral cortex of patients with multiple sclerosis (MS), P2Y12 expression is absent in microglia/macrophages within the lesion, ${ }^{33}$ but it is expressed in cells surrounding brain lesions. This decrease in P2Y12 expression correlated with the extent of demyelination. In our study, we confirmed that in the active MS lesion, P2Y12 was not expressed (not shown), but it was observed in $\mathrm{CD}^{+} 8^{+}$cells in areas adjacent to the lesion (figure e-6A). P2Y12 was not expressed in other glial cells such as astrocytes (figure e-6B).

Our in vitro and in situ observations prompted additional studies to examine how a $\mathrm{T}_{\mathrm{h}} 2 / \mathrm{M} 2$ environment might affect P2Y12 expression in situ. In vivo studies have convincingly shown that parasitic infection can promote both $\mathrm{T}_{\mathrm{h}} 2$ and M2-polarized 


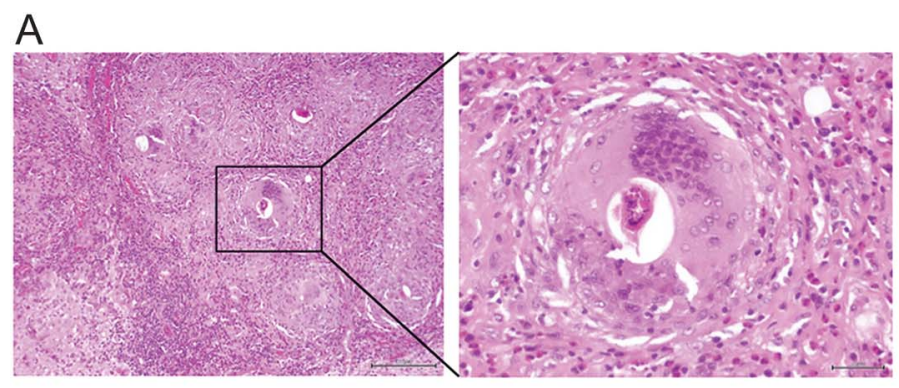

B

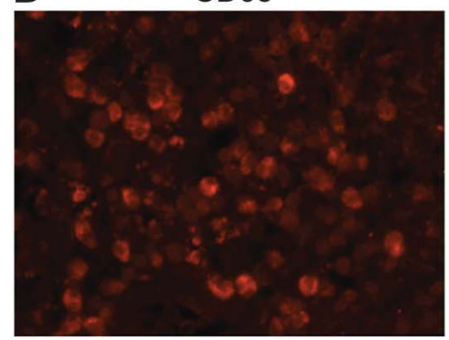

C

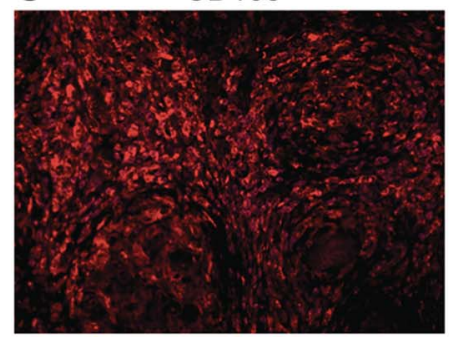

$\mathrm{P} 2 \mathrm{Y} 12$

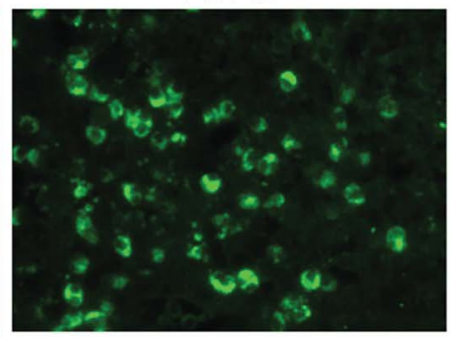

$\mathrm{P} 2 \mathrm{Y} 12$

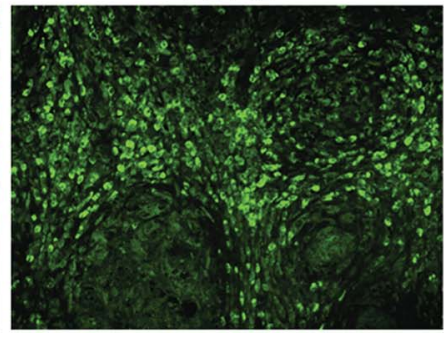

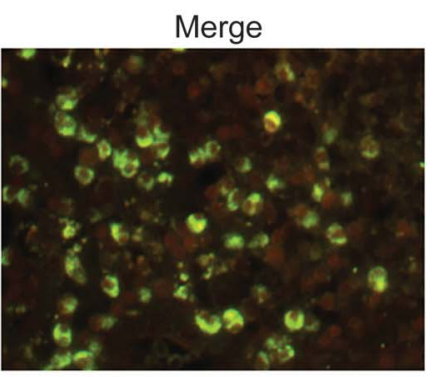

Merge

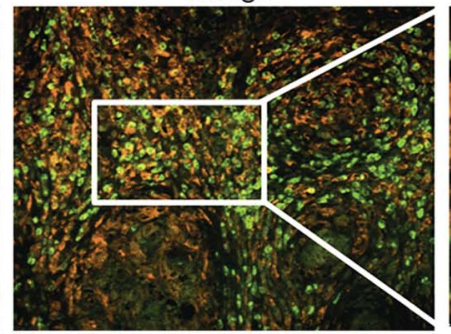

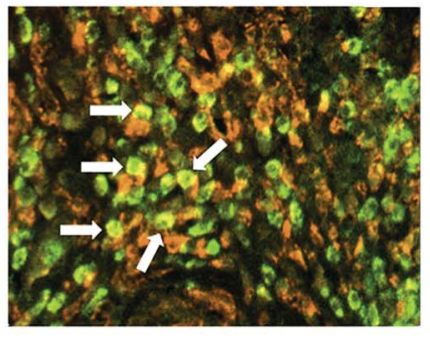

In a case of Schistosoma mekongi infection, hematoxylin and eosin-stained sections show evidence of the brain parenchyma containing granulomas and helminthic ova surrounded by inflammatory cells (A). Within the granulomas, immunohistochemistry experiments showed the presence of several CD68 ${ }^{+}$ (non-myeloid cell-specific) cells (B) and CD163+ (M2 marker) (C) cells that positively stained for P2Y12. White arrows in the higher magnified panel point toward double-positive $\mathrm{CD} 163^{+} / \mathrm{P} 2 \mathrm{Y} 12+$ cells.

phenotypes $^{34-36}$ and can attract the migration of M2 macrophages to parasite eggs and chitin. ${ }^{37}$ Using a rare case of human $S$ mekongi infection of the brain, ${ }^{22}$ we confirmed that $\mathrm{P} 2 \mathrm{Y} 12+/ \mathrm{CD} 163^{+} \mathrm{M} 2$ cells were present in regions circumscribing helminthic ova (figure 6). It is interesting that previous associations have been made between parasite infection and diseaserelevant immune responses in MS. In MS, patients infected by helminths have been shown to harbor decreased proinflammatory $\mathrm{T}$-cell responses ${ }^{38}$ and increased inflammation-resolving regulatory $\mathrm{B}$ cells producing IL-10, brain-derived neurotrophic factor, and nerve growth factor. ${ }^{39}$ In addition, compared to uninfected patients, clinical outcome measures are improved in helminth-infected patients with MS. ${ }^{40-42}$

In this report, we have confirmed that P2Y12 is selectively expressed on human microglia and can be used as a marker to distinguish CNS-resident microglia from blood-derived myeloid cells. P2Y12 expression on microglia is dependent on different modes of activation such that an inflammatory environment decreases expression whereas a $T_{h} 2 / M 2$ microenvironment increases expression. In response to their endogenous ligand, ADP, human microglia rapidly increase $\left[\mathrm{Ca}^{+}\right]_{\mathrm{i}}$, release proinflammatory cytokines, and display significant migratory ability. Application of a selective P2Y12 receptor antagonist was demonstrated to reverse these functions. Our findings provide insight into how the functional properties of microglia differ from peripheralderived macrophages in the inflamed CNS. These properties are in part controlled by their relative level of P2Y12 expression, which may provide a novel targeting strategy for treating CNS inflammatory conditions.

\section{AUTHOR CONTRIBUTIONS}

Craig S. Moore: drafting/revising the manuscript, study concept or design, analysis or interpretation of data, contribution of vital reagents/ tools/patients, acquisition of data, statistical analysis, study supervision. Ariel Ase: drafting/revising the manuscript, analysis or interpretation of data, acquisition of data, statistical analysis. Angham Kinsara: study concept or design, analysis or interpretation of data, statistical analysis. Vijayaraghava T.S. Rao: study concept or design, analysis or interpretation of data, contribution of vital reagents/tools/patients, acquisition of data, statistical analysis, study supervision. Mackenzie Michell- 
Robinson: analysis or interpretation of data, acquisition of data. Soo Yuen Leong: analysis or interpretation of data, acquisition of data. Oleg Butovsky: drafting/revising the manuscript, study concept or design, analysis or interpretation of data, contribution of vital reagents/tools/patients. Samuel K. Ludwin: drafting/revising the manuscript, study concept or design, analysis or interpretation of data, contribution of vital reagents/tools/patients, acquisition of data, study supervision. Philippe Séguéla: study concept or design, analysis or interpretation of data. Amit Bar-Or: drafting/revising the manuscript, study concept or design, analysis or interpretation of data, contribution of vital reagents/tools/patients, study supervision, obtaining funding. Jack P. Antel: drafting/revising the manuscript, study concept or design, analysis or interpretation of data, acquisition of data.

\section{ACKNOWLEDGMENT}

The authors thank Dr. E.S. Johnson, Department of Pathology, University of Alberta, Edmonton, Canada, for providing sections of the human CNS case of schistosomiasis. The authors also thank Manon Blain, Ellie McCrea, and Farrah Jalili for technical assistance; Dr. Bradford Poulos, director of the Human Fetal Tissue Repository at Albert Einstein College of Medicine; Mr. J. Bradley Williams for reviewing the manuscript; and Drs. André Olivier, Jeffery Hall, and Kevin Petrecca for providing adult human brain tissue.

\section{STUDY FUNDING}

No targeted funding reported.

\section{DISCLOSURE}

C.S. Moore holds a patent for diagnostic marker for interferon responsiveness in MS. A.R. Ase, A. Kinsara, and V.T.S. Rao report no disclosures. M. Michell-Robinson has received research support from Canadian Institutes of Health Research. S.Y. Leong reports no disclosures. O. Butovsky has received travel funding and/or speaker honoraria from Einstein Institute of Medicine, NY Academy of Sciences, and University of California, Irvine; holds a patent for the use of miR-155 inhibitors as a therapy for ALS; has filed a patent application to use APOE inhibitors in ALS; and received research support from MiRagen Therapeutics, NIH, Nancy Davis Foundation for MS, National MS Society, and ALS Assocation. S.K. Ludwin has received honorarium from the Myelin Repair Foundation. P. Séguéla reports no disclosures. A. Bar-Or is on the scientific advisory board for Diogenix, Ono Pharmacia, Receptos, Roche, Novartis, GSK, and Guthy Jackson Greater Good Foundation; has received travel funding and/or speaker honoraria from Diogenix, Ono Pharacia, Receptos, Roche, Novartis, and GSK; is on the editorial board for Neurology and Clinical and Experimental Neuorimmunology; has consulted for Diogenix, Ono Pharmacia, Receptos, Roche, Novartis, and GSK; and has received research support from Novartis and Genzyme-Sanofi. J.P. Antel is on the scientific advisory board for Sanofi Aventis, TEVA Neuroscience, Biogen Idec, Genzyme, Cleveland Clinic Foundation, and Novartis; has received travel funding and/or speaker honoraria from TEVA Neuroscience, Novartis, EMD Serono, and Biogen Idec; is on the editorial board for Multiple Sclerosis Journal, Journal of Neuroimmunology, and Journal of Neuroscience Research; receives publishing royalties from Oxford University Press; has consulted for EMD Serono, Novartis, Biogen Idec, TEVA Neuroscience, and Sanofi Aventis; and has received research support from Novartis, CIHR, and Multiple Sclerosis Society of Canada. Go to Neurology.org/nn for full disclosure forms.

Received November 21, 2014. Accepted in final form January 15, 2015.

\section{REFERENCES}

1. Moore CS, Rao VT, Durafourt BA, et al. miR-155 as a multiple sclerosis-relevant regulator of myeloid cell polarization. Ann Neurol 2013;74:709-720.

2. Durafourt BA, Moore CS, Zammit DA, et al. Comparison of polarization properties of human adult microglia and blood-derived macrophages. Glia 2012;60:717-727.
3. Lambert C, Ase AR, Seguela P, Antel JP. Distinct migratory and cytokine responses of human microglia and macrophages to ATP. Brain Behav Immun 2010;24:1241-1248.

4. Williams K, Ulvestad E, Antel JP. B7/BB-1 antigen expression on adult human microglia studied in vitro and in situ. Eur J Immunol 1994;24:3031-3037.

5. Williams K, Bar-Or A, Ulvestad E, Olivier A, Antel JP, Yong VW. Biology of adult human microglia in culture: comparisons with peripheral blood monocytes and astrocytes. J Neuropathol Exp Neurol 1992;51:538-549.

6. Seguin R, Biernacki K, Prat A, et al. Differential effects of Th1 and Th2 lymphocyte supernatants on human microglia. Glia 2003;42:36-45.

7. Evans TA, Barkauskas DS, Myers JT, et al. High-resolution intravital imaging reveals that blood-derived macrophages but not resident microglia facilitate secondary axonal dieback in traumatic spinal cord injury. Exp Neurol 2014;254: 109-120.

8. Saederup N, Cardona AE, Croft K, et al. Selective chemokine receptor usage by central nervous system myeloid cells in CCR2-red fluorescent protein knock-in mice. PLoS One 2010;5:e13693.

9. Ajami B, Bennett JL, Krieger C, McNagny KM, Rossi FM. Infiltrating monocytes trigger EAE progression, but do not contribute to the resident microglia pool. Nat Neurosci 2011;14:1142-1149.

10. Butovsky O, Jedrychowski MP, Moore CS, et al. Identification of a unique TGF-beta-dependent molecular and functional signature in microglia. Nat Neurosci 2014;17: 131-143.

11. Giossi A, Pezzini A, Del Zotto E, et al. Advances in antiplatelet therapy for stroke prevention: the new P2Y12 antagonists. Curr Drug Targets 2010;11:380-391.

12. Haynes SE, Hollopeter G, Yang G, et al. The P2Y12 receptor regulates microglial activation by extracellular nucleotides. Nat Neurosci 2006;9:1512-1519.

13. Sieger D, Moritz C, Ziegenhals T, Prykhozhij S, Peri F. Long-range Ca2+ waves transmit brain-damage signals to microglia. Dev Cell 2012;22:1138-1148.

14. Miron VE, Boyd A, Zhao JW, et al. M2 microglia and macrophages drive oligodendrocyte differentiation during CNS remyelination. Nat Neurosci 2013;16:1211-1218.

15. Shechter R, Miller O, Yovel G, et al. Recruitment of beneficial M2 macrophages to injured spinal cord is orchestrated by remote brain choroid plexus. Immunity 2013;38: 555-569.

16. Mantovani A, Biswas SK, Galdiero MR, Sica A, Locati M. Macrophage plasticity and polarization in tissue repair and remodelling. J Pathol 2013;229:176-185.

17. Durafourt BA, Moore CS, Blain M, Antel JP. Isolating, culturing, and polarizing primary human adult and fetal microglia. Methods Mol Biol 2013;1041:199-211.

18. Livak KJ, Schmittgen TD. Analysis of relative gene expression data using real-time quantitative PCR and the 2(-Delta Delta C(T)) Method. Methods 2001;25:402-408.

19. Li J, Zhuang W, Cong L, et al. Cyclophilin A from Schistosoma japonicum promotes a Th2 response in mice. Parasit Vectors 2013;6:330.

20. Smith KA, Maizels RM. IL-6 controls susceptibility to helminth infection by impeding Th2 responsiveness and altering the Treg phenotype in vivo. Eur J Immunol 2014; 44:150-161.

21. van der Werf N, Redpath SA, Phythian-Adams AT, et al. Th2 responses to helminth parasites can be therapeutically 
enhanced by, but are not dependent upon, GITR-GITR ligand costimulation in vivo. J Immunol 2011;187:1411-1420.

22. Houston S, Kowalewska-Grochowska K, Naik S, McKean J, Johnson ES, Warren K. First report of Schistosoma mekongi infection with brain involvement. Clin Infect Dis 2004;38:e1-6.

23. Gautier EL, Shay T, Miller J, et al. Gene-expression profiles and transcriptional regulatory pathways that underlie the identity and diversity of mouse tissue macrophages Nat Immunol 2012;13:1118-1128.

24. Butovsky O, Siddiqui S, Gabriely G, et al. Modulating inflammatory monocytes with a unique microRNA gene signature ameliorates murine ALS. J Clin Invest 2012;122:3063-3087.

25. Hollopeter G, Jantzen HM, Vincent D, et al. Identification of the platelet ADP receptor targeted by antithrombotic drugs. Nature 2001;409:202-207.

26. Sasaki Y, Hoshi M, Akazawa C, et al. Selective expression of Gi/o-coupled ATP receptor P2Y12 in microglia in rat brain. Glia 2003;44:242-250.

27. Orr AG, Orr AL, Li XJ, Gross RE, Traynelis SF. Adenosine $\mathrm{A}(2 \mathrm{~A})$ receptor mediates microglial process retraction. Nat Neurosci 2009;12:872-878.

28. De Simone R, Niturad CE, De Nuccio C, AjmoneCat MA, Visentin S, Minghetti L. TGF-beta and LPS modulate ADP-induced migration of microglial cells through P2Y1 and P2Y12 receptor expression. J Neurochem 2010;115:450-459.

29. Crain JM, Nikodemova M, Watters JJ. Expression of P2 nucleotide receptors varies with age and sex in murine brain microglia. J Neuroinflammation 2009;6:24.

30. Bauer SM. ADP receptor antagonists as antiplatelet therapeutics. Expert Opin Emerg Drugs 2003;8:93-101.

31. Murray PJ, Allen JE, Biswas SK, et al. Macrophage activation and polarization: nomenclature and experimental guidelines. Immunity 2014;41:14-20.
32. Desestret V, Riou A, Chauveau F, et al. In vitro and in vivo models of cerebral ischemia show discrepancy in therapeutic effects of M2 macrophages. PLoS One 2013;8: e67063.

33. Amadio S, Montilli C, Magliozzi R, Bernardi G, Reynolds R, Volonte C. P2Y12 receptor protein in cortical gray matter lesions in multiple sclerosis. Cereb Cortex 2010;20:1263-1273.

34. Zhu J, Xu Z, Chen X, et al. Parasitic antigens alter macrophage polarization during Schistosoma japonicum infection in mice. Parasit Vectors 2014;7:122.

35. Ishii $\mathrm{M}$, Wen $\mathrm{H}$, Corsa $\mathrm{CA}$, et al. Epigenetic regulation of the alternatively activated macrophage phenotype. Blood 2009;114:3244-3254.

36. Fairfax K, Nascimento M, Huang SC, Everts B, Pearce EJ. Th2 responses in schistosomiasis. Semin Immunopathol 2012;34:863-871.

37. Ni Gabhann J, Hams E, Smith S, et al. Btk regulates macrophage polarization in response to lipopolysaccharide. PLoS One 2014;9:e85834.

38. Correale J, Farez MF. Does helminth activation of toll-like receptors modulate immune response in multiple sclerosis patients? Front Cell Infect Microbiol 2012;2:112.

39. Correale J, Farez M, Razzitte G. Helminth infections associated with multiple sclerosis induce regulatory B cells. Ann Neurol 2008;64:187-199.

40. Correale J, Farez MF. The impact of parasite infections on the course of multiple sclerosis. J Neuroimmunol 2011; 233:6-11.

41. Correale J, Farez MF. The impact of environmental infections (parasites) on MS activity. Mult Scler 2011;17: 1162-1169.

42. Correale J, Farez M. Association between parasite infection and immune responses in multiple sclerosis. Ann Neurol 2007;61:97-108. 


\section{Neurology \\ Neuroimmunology \& Neuroinflammation}

P2Y12 expression and function in alternatively activated human microglia

Craig S. Moore, Ariel R. Ase, Angham Kinsara, et al.

Neurol Neuroimmunol Neuroinflamm 2015;2;

DOI 10.1212/NXI.0000000000000080

This information is current as of March 19, 2015

\section{Updated Information \&}

Services

Supplementary Material

References

Citations

Errata

Permissions \& Licensing

Reprints including high resolution figures, can be found at:

http://nn.neurology.org/content/2/2/e80.full.html

Supplementary material can be found at:

http://nn.neurology.org/content/suppl/2015/03/19/2.2.e80.DC1

This article cites 42 articles, 2 of which you can access for free at: http://nn.neurology.org/content/2/2/e80.full.html\#\#ref-list-1

This article has been cited by 2 HighWire-hosted articles: http://nn.neurology.org/content/2/2/e80.full.html\#\#otherarticles

An erratum has been published regarding this article. Please see next page or: /content/2/3/e106.full.pdf

Information about reproducing this article in parts (figures,tables) or in its entirety can be found online at:

http://nn.neurology.org/misc/about.xhtml\#permissions

Information about ordering reprints can be found online: http://nn.neurology.org/misc/addir.xhtml\#reprintsus

Neurol Neuroimmunol Neuroinflamm is an official journal of the American Academy of Neurology.

Published since April 2014, it is an open-access, online-only, continuous publication journal. Copyright $(\subseteq$ 2015 American Academy of Neurology. All rights reserved. Online ISSN: 2332-7812.

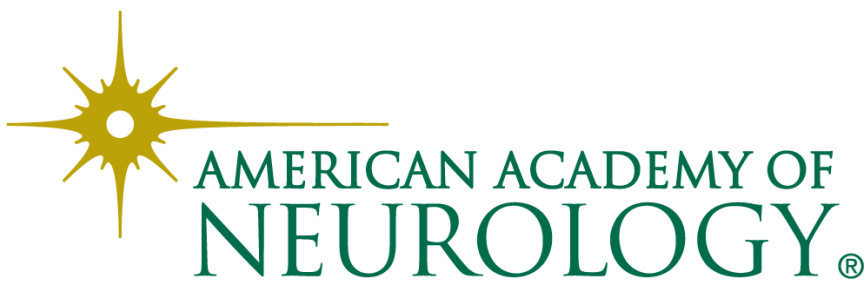




\section{CORRECTION}

P2Y12 expression and function in alternatively activated human microglia

In the article "P2Y12 expression and function in alternatively activated human microglia" by C.S. Moore et al. (Neurology ${ }^{\circledR}$ Neuroimmunology \& Neuroinflammation 2015;2:e80), there is an error in figure 6, panel C, first image. The image should have been titled CD163. The editorial staff regrets the error. 